\title{
Establishment of a hepatocyte steatosis model using Chang liver cells
}

\author{
D. Yan ${ }^{1}$, Q.L. Dou ${ }^{3}$, Z. Wang ${ }^{4}$ and Y.Y. Wei ${ }^{2}$
}

'Department of Pharmacology, Basic Medical College, Xinjiang Medical University, Xinjiang, China

${ }^{2}$ Department of physiology, Basic Medical College, Xinjiang Medical University, Xinjiang, China

${ }^{3} \mathrm{ICU}$, The First Affiliated Hospital of Xinjiang Medical University, Xinjiang, China

${ }^{4}$ Section of Laboratory Animal Research, First Affiliated Hospital,

Xinjiang Medical University, Xinjiang, China

Corresponding author: Y.Y. Wei

E-mail: weiyuanyuan__@163.com

Genet. Mol. Res. 14 (4): 15224-15232 (2015)

Received June 15, 2015

Accepted September 24, 2015

Published November 25, 2015

DOI http://dx.doi.org/10.4238/2015.November.25.10

ABSTRACT. The objective of this study was to explore the experimental conditions for hepatocellular steatosis models of Chang liver cells induced by oleic acid (OA). For that, Chang liver cells were induced by different concentrations of OA for different periods. The MTT assay was used to detect hepatic cell activity, the Oil Red O staining was used to observe intracellular lipid droplets accumulation, and the glycerol phosphate oxidase method was used to detect the triglyceride (TG) content in the Chang liver cell. The hepatocellular steatosis models of Chang liver cell were established successfully by inducing with $0.2 \mathrm{mM}$ OA for $24 \mathrm{~h}$. TG content in model cells was $379.98 \pm 23.19 \mathrm{mg} / \mathrm{g}$, which is significantly different from control cells $(185.03 \pm 12.68 \mathrm{mg} / \mathrm{g} ; \mathrm{P}<0.01)$. These were considered proper conditions for establishing hepatocellular steatosis models of Chang liver cells, producing a reliable model for nonalcoholic fatty liver disease research.

Key words: Fatty liver; Steatosis model; Cells; Oleic acid; Chang liver cells 


\section{INTRODUCTION}

The incidence of nonalcoholic fatty liver disease (NAFLD) has been increasing gradually. In a relatively short time, NAFLD can cause irreversible liver damage, including $25 \%$ liver fibrosis and 1.5-8.0\% liver cirrhosis (Kobashi-Margáin et al., 2010), which has an important and hidden dangerous effect on health. Currently, the studies on in vitro cell models of NAFLD mainly use oleic acid (OA) to induce fat deposition in hepatocytes (Feldstein et al., 2004; Lv et al., 2011). Most studies use HepG2 as model cells, due to their oncological characteristics such as culturing, easy passaging, and the ability to be repeatedly frozen (Day and James, 1998; Gómez-Lechón et al., 2007). Indeed, there are few studies about establishing fatty degeneration models using human normal cells, and no reports about establishing it using Chang liver cells. Since the hepatic fatty degeneration of NAFLD usually occurs in normal cells, and not tumorous ones, there is a practical advantage of investigating and establishing models using normal hepatocyte cells. In order to provide a new model to study NAFLD, we chose Chang liver cells to establish fatty degeneration models through OA inducing, and investigated the appropriate concentrations and reaction times.

\section{MATERIAL AND METHODS}

\section{Material and equipment}

The Chang liver cell line was obtained from Shanghai Cellular Institute of the Chinese Academy of Sciences. Fetal bovine serum (FBS) was obtained from Zhejiang Tianhang Biological Technology Co., Ltd., China. Dulbecco's modified Eagle medium (DMEM) was obtained from Thermo Fisher Scientific Inc., USA. The triglyceride (TG) assay kit was obtained from Xiamen InTec Technology Co., Ltd. Trypsin, oleic acid, 3-(4,5-dimethylthiazol-2-yl)-2,5-diphenyltetrazolium bromide (MTT), bicinchoninic acid (BCA) protein assay, and Oil Red O were obtained from SigmaAldrich, USA. The enzyme-labeled instrument was obtained from Bio-Rad Laboratories, Inc., USA and the fluorescence microscope was obtained from Olympus Imaging Co., Ltd., Japan.

\section{Cell culture}

Chang liver cells were cultured in $4 \mathrm{~mL}$ DMEM containing $10 \% \mathrm{FBS}$ at $37^{\circ} \mathrm{C}$ with $5 \% \mathrm{CO}_{2}$. When the cells grew to $\sim 80-90 \%$ confluence, one passage was taken in $24 \sim 48 \mathrm{~h}$, according to $1: 2$ or $1: 3$, passaging to the new culture bottles. Selected the well growing Chang liver cells to culture on a 96-well plate according to 104 each well. Then, $200 \mu \mathrm{L}$ medium was added to each well, and the plate was placed at $37^{\circ} \mathrm{C}$ with $5 \% \mathrm{CO}_{2}$ for $24 \mathrm{~h}$. These cultured cells were subjected to different concentrations of $\mathrm{OA}(0.2,0.4,0.6,0.8,1.0,2.0,3.0,4.0 \mathrm{mM})$, with six wells for each concentration, and then stained with Oil Red $O$. They were observed under the microscope at 24,48 , and 72 h. According to the results of the MTT assay, the degree of fatty degeneration of the cells was determined, and we confirmed the best concentration and reaction time of OA.

\section{Cell morphology observation}

The growing status and morphological changes of cells was observed with an inverted microscope. Histologically, a formation of more than $5 \%$ of fat droplets in hepatocytes was considered as a fatty liver (Kleiner et al., 2005). 


\section{Cell viability through the MTT assay}

Chang liver cells were cultured on a 96-well plate with $5 \mathrm{~mL}$ RPMI-1640 medium containing $10 \%$ FBS. When the cells grew to $\sim 80-90 \%$ confluence, one passage was taken in $\sim 24-$ $48 \mathrm{~h}$, according to $1: 2$ or $1: 3$, passaging them to new culture bottles. When the cells were in the exponential growth phase, they were passaged onto a 96-well plate according to 104 each well. Then, $200 \mu \mathrm{l}$ medium were added to each well, and the plate was placed at $37^{\circ} \mathrm{C}$ with $5 \% \mathrm{CO}_{2}$ for $24 \mathrm{~h}$. The adherent state of the cells was observed. The cells were divided into control group and groups with different OA concentrations, with 6 wells in each group. At 24, 48, and 72 h, 20 l MTT were added, the mixture was incubated for $4 \mathrm{~h}$, and then the reaction was terminated. The solution was absorbed and $100 \mu \mathrm{l}$ DMSO were added to each well, after which the plate was shaken at an oscillator for $10 \mathrm{~min}$ to dissolve the substance. The OD value was measured using an enzymemarked instrument at $490 \mathrm{~nm}$. Cell growth curves were obtained from these measurements.

\section{Degree of fatty degeneration}

Cell slides were stained with Oil Red O and observed using a light microscope. Cells with orange fat droplets were counted as undergoing fatty degeneration. Under a high power field, six pictures were randomly selected and 100 cells in each picture were assessed to be normal or undergoing fatty degeneration. These were used to calculate the average percentage of fatty degeneration.

\section{Detection of TG in cells}

Chang liver cells were cultured on a 6-well plate and divided into different groups with different treatments mentioned above. The cells were collected after $24 \mathrm{~h}$ and washed twice with PBS. Then, the RIPA lysis buffer was added, and the plate was shaken and placed on ice for 30 $\min$. After full reaction, the contents of each well were centrifuged at $4^{\circ} \mathrm{C}$, with $14,000 \mathrm{rpm}$ for 10 min, and the supernatant was extracted. The protein and TG contents were determined using the BCA protein assay and the glycerol phosphate oxidase method, respectively. The OD was measured at 500 550 nm, and the comparison with the calibration curve allowed the determination of the TG concentration.

\section{Statistics}

All the data were analyzed with SPSS (version 13.0; IBM Corporation, USA), and reported as mean $\pm \mathrm{SD}$. One-way ANOVA was used to comparing between multiple sample means. Significant differences were considered when $\mathrm{P}<0.05$.

\section{RESULTS}

\section{Cytomorphology observation}

In the control group, the cells were densely packed, with clear edge. After OA induction, the Chang liver cells grew vigorously with clear edge, and most of the cells were round with a large nucleus. Many nucleuses were crowed, giving the appearance of signet-ring cells. 


\section{Cell viability through the MTT assay}

The OD values are shown in Table 1 and the growth curves are shown in Figure 1. These results show that, when the concentration of $\mathrm{OA}$ is $0.2 \mathrm{mM}$, there is no inhibition on the growing of Chang liver cells. The degree of proliferation in the $0.2 \mathrm{mM}$ group was close to the control. As the concentration of $\mathrm{OA}$ and reaction time increased, the growing of the cells was inhibited with different degrees.

\begin{tabular}{|c|c|c|c|c|}
\hline \multirow[t]{2}{*}{ Groups } & \multirow[t]{2}{*}{$\mathrm{N}$} & \multicolumn{3}{|c|}{ OD } \\
\hline & & $24 \mathrm{~h}$ & $48 \mathrm{~h}$ & $72 \mathrm{~h}$ \\
\hline DMSO & 6 & $0.605 \pm 0.037$ & $0.63 \pm 0.039$ & $0.645 \pm 0.038$ \\
\hline Control & 6 & $0.619 \pm 0.046$ & $0.627 \pm 0.042$ & $0.662 \pm 0.018$ \\
\hline $0.2 \mathrm{mM} O A$ & 6 & $0.610 \pm 0.013$ & $0.613 \pm 0.018$ & $0.616 \pm 0.019$ \\
\hline $0.4 \mathrm{mM} \mathrm{OA}$ & 6 & $0.619 \pm 0.003$ & $0.524 \pm 0.006$ & $0.426 \pm 0.006$ \\
\hline $0.6 \mathrm{mM} \mathrm{OA}$ & 6 & $0.604 \pm 0.014$ & $0.521 \pm 0.009$ & $0.414 \pm 0.013$ \\
\hline $0.8 \mathrm{mM} \mathrm{OA}$ & 6 & $0.551 \pm 0.054$ & $0.490 \pm 0.027$ & $0.357 \pm 0.052$ \\
\hline $1 \mathrm{mM} O \mathrm{~A}$ & 6 & $0.550 \pm 0.013$ & $0.484 \pm 0.013$ & $0.379 \pm 0.021$ \\
\hline $2 \mathrm{mM} O A$ & 6 & $0.556 \pm 0.041$ & $0.424 \pm 0.049$ & $0.322 \pm 0.050$ \\
\hline $3 \mathrm{mM} O A$ & 6 & $0.516 \pm 0.018$ & $0.345 \pm 0.046$ & $0.340 \pm 0.038$ \\
\hline $4 \mathrm{mM} O A$ & 6 & $0.485 \pm 0.059$ & $0.342 \pm 0.042$ & $0.309 \pm 0.023$ \\
\hline
\end{tabular}

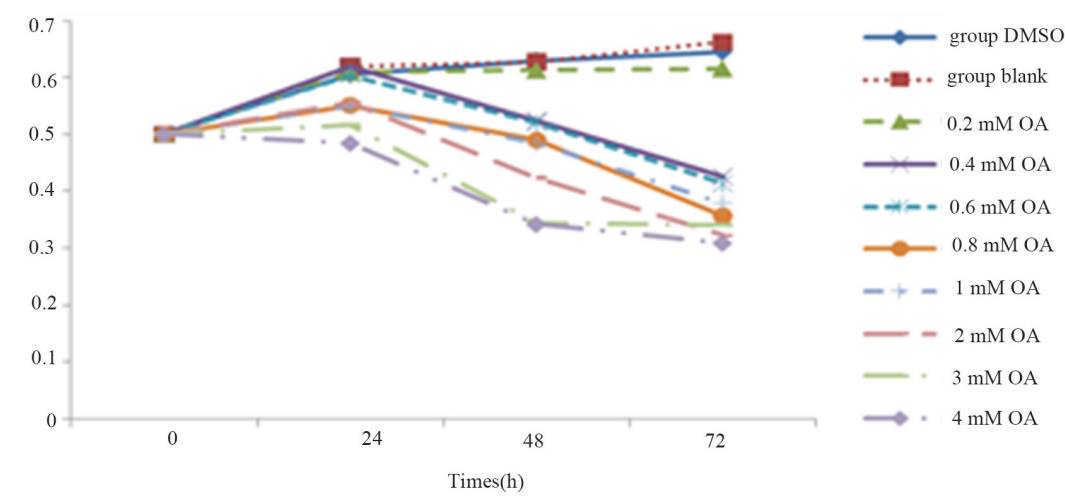

Figure 1. Growth curve of Chang liver cells at different OA concentrations.

\section{Lipid accumulation through Oil Red $O$ staining}

The results of staining with Oil Red $\mathrm{O}$ showed that, in the control group, the cell nucleus appeared violet blue and with clear edge, without fat droplets inside the cells (Figure 2). When the concentration of OA was $0.2 \mathrm{mM}$ or $0.4 \mathrm{mM}$, there were fat droplets with different sizes inside the cells, even in fusion (Figures 3 and 4). When the concentration of OA was 0.6, 0.8, 1.0, or $2.0 \mathrm{mM}$ (Figures $5,6,7$, and 8 , respectively), there were more fat droplets in the cells, which led to an increased toxicity induced by OA. At even larger concentrations, the edge of the cells was not clear, the cells presented a different shape, and the number of cells decreased (Figures 9 and 10). The proportion of fatty degeneration at different OA concentrations and different times is shown in Table 2. The establishing condition of fatty degeneration in Chang liver cells was culturing in $0.2 \mathrm{mM}$ OA for $24 \mathrm{~h}$. 
D. Yan et al.

15228

Figure 2. Control group (200X magnification).
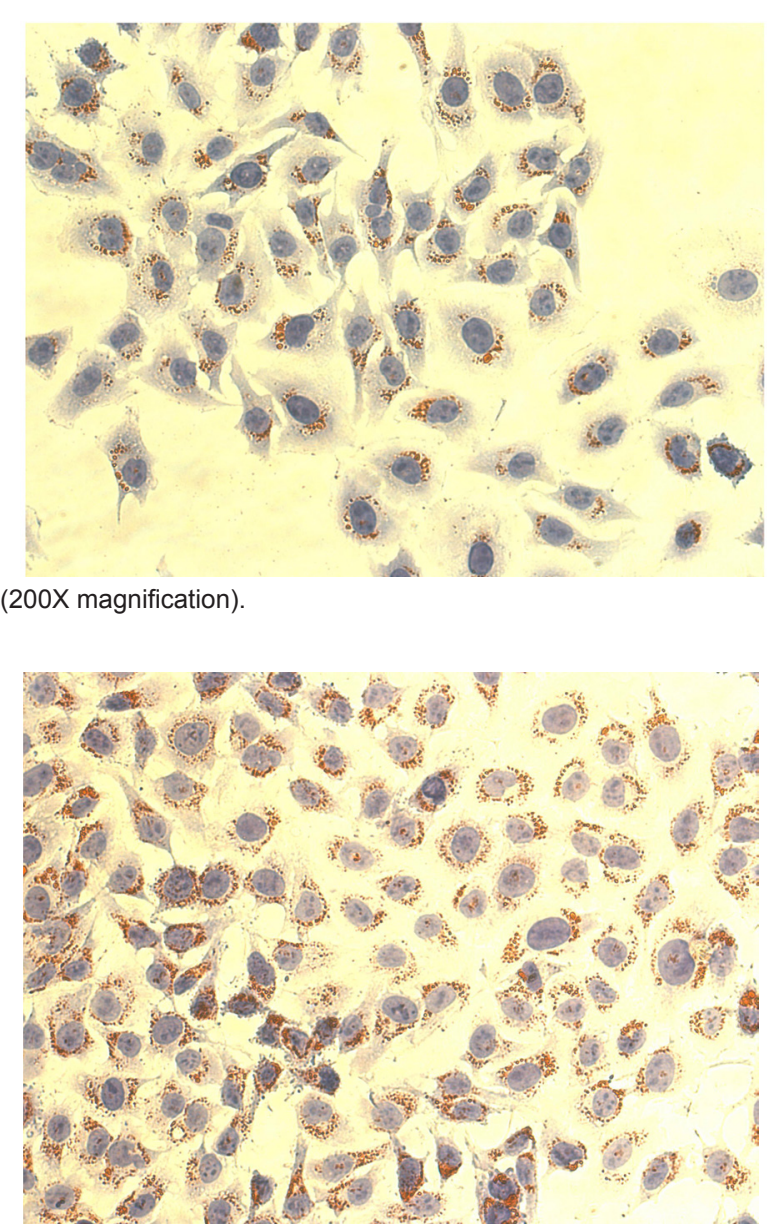

Figure 3. $0.2 \mathrm{mM} \mathrm{OA}$ (200X magnification).
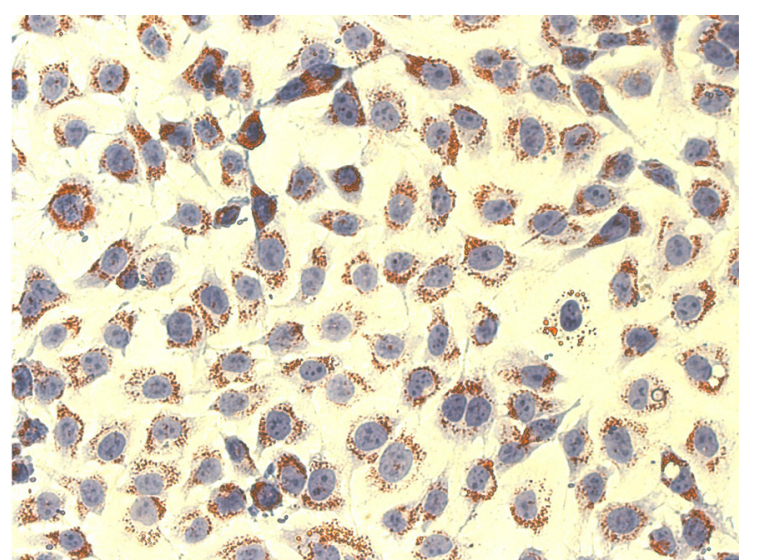

Figure 4. 0.4 mM OA (200X magnification). 


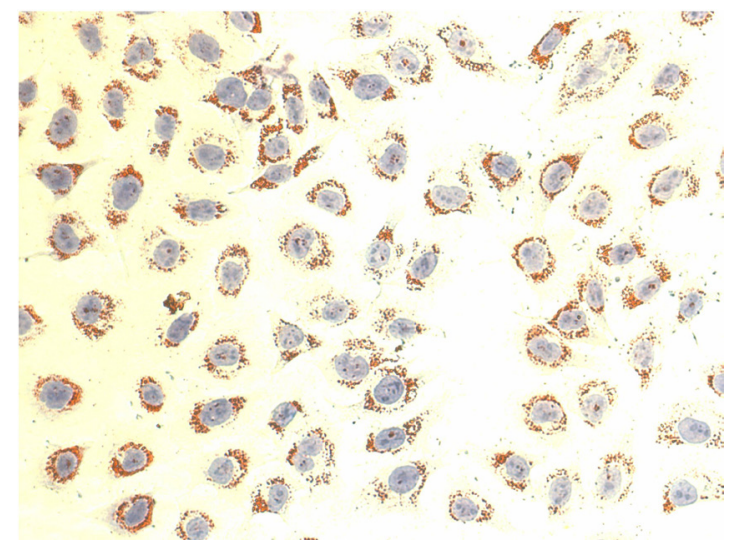

Figure 5. $0.6 \mathrm{mM}$ OA (200X magnification).

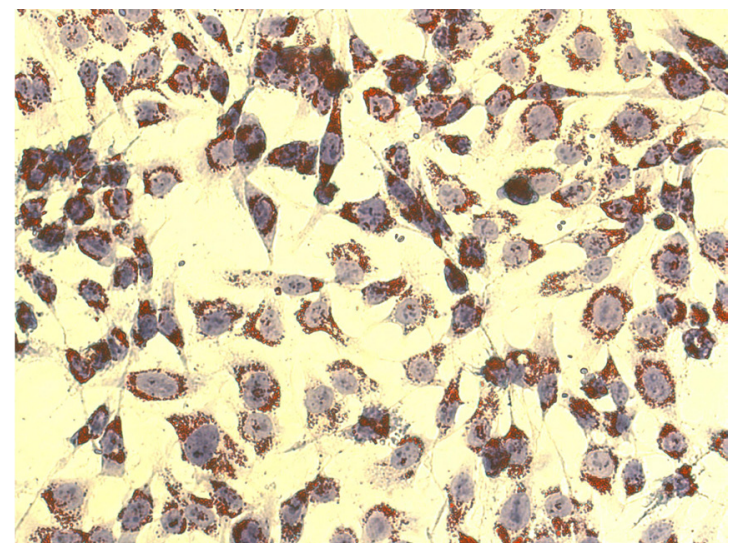

Figure 6. $0.8 \mathrm{mM}$ OA (200X magnification).

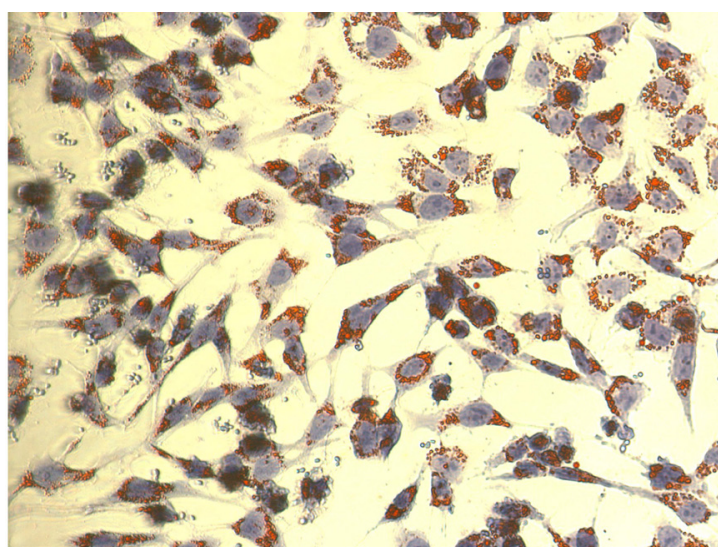

Figure 7. $1 \mathrm{mM}$ OA (200X magnification). 
Figure 8. 2 mM OA (200X magnification).
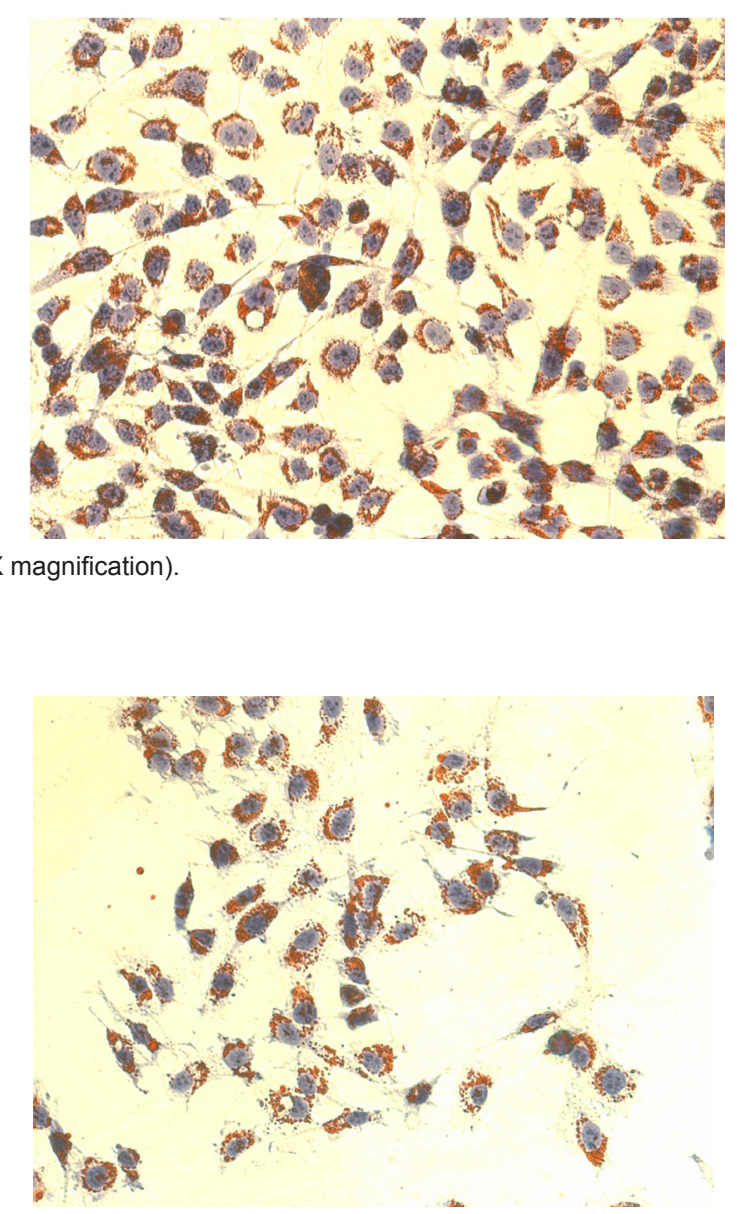

Figure 9. $3 \mathrm{mM} \mathrm{OA} \mathrm{(200X} \mathrm{magnification).}$

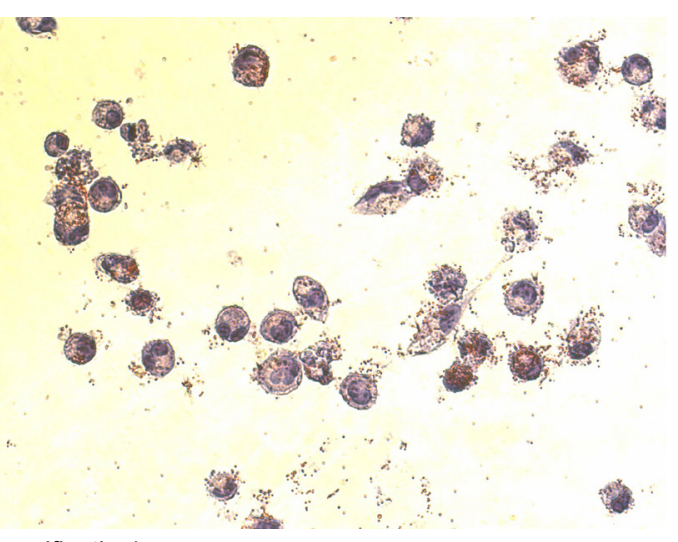

Figure 10. 4 mM OA (200X magnification). 
Table 2. Proportion of fatty degeneration at different OA concentrations and different times.

\begin{tabular}{|c|c|c|c|c|}
\hline \multirow[t]{2}{*}{ Groups } & \multirow[t]{2}{*}{$\mathrm{N}$} & \multicolumn{3}{|c|}{ Proportion of fatty degeneration (\%) } \\
\hline & & $24 \mathrm{~h}$ & $48 \mathrm{~h}$ & $72 \mathrm{~h}$ \\
\hline $0.2 \mathrm{mM} \mathrm{OA}$ & 6 & $76.34 \pm 3.38$ & $78.54 \pm 3.86$ & $80.03 \pm 4.19$ \\
\hline $0.4 \mathrm{mM} \mathrm{OA}$ & 6 & $79.65 \pm 3.76$ & $71.24 \pm 3.65$ & $67.26 \pm 3.76$ \\
\hline $0.6 \mathrm{mM} \mathrm{OA}$ & 6 & $80.36 \pm 4.41$ & $58.41 \pm 2.89$ & $51.14 \pm 2.53$ \\
\hline $0.8 \mathrm{mM} \mathrm{OA}$ & 6 & $64.82 \pm 5.46$ & $59.30 \pm 2.73$ & $53.57 \pm 3.02$ \\
\hline $1 \mathrm{mM} O \mathrm{~A}$ & 6 & $55.04 \pm 3.09$ & $46.24 \pm 2.13$ & $42.79 \pm 2.21$ \\
\hline $2 \mathrm{mM} O A$ & 6 & $55.68 \pm 4.10$ & $42.64 \pm 2.79$ & $40.25 \pm 3.50$ \\
\hline $3 \mathrm{mM} O A$ & 6 & $51.66 \pm 3.81$ & $34.45 \pm 2.46$ & $30.40 \pm 2.38$ \\
\hline $4 \mathrm{mM} O A$ & 6 & $41.53 \pm 2.59$ & $29.42 \pm 3.02$ & $22.49 \pm 2.63$ \\
\hline
\end{tabular}

\section{Changes of TG content in Chang liver cells}

When comparing the control group with the fatty degeneration Chang liver cells model (cultured in $0.2 \mathrm{mM} \mathrm{OA}$ for $24 \mathrm{~h}$ ), it was observed that the TG content increased significantly $(\mathrm{P}<$ 0.01 ) in the models, which is in accordance with the requirements for NAFLD models. (Table 3).

Table 3. Effect of pomegranate polyphenols on TG in the cells with steatosis induced by OA.

\begin{tabular}{llr}
\hline Groups & N & TG $(\mathrm{mg} \cdot \mathrm{g}-1)$ \\
\hline Control & 6 & $185.03 \pm 12.68$ \\
Chang liver model & 6 & $379.98 \pm 23.19^{* *}$ \\
\hline
\end{tabular}

${ }^{* *} \mathrm{P}<0.01$.

\section{DISCUSSION}

Currently, researchers establish the HepG2 hepatoma cells and L02 human hepatocytes to be the models of hepatocyte steatosis. In contrast, we used the human normal hepatocyte Chang liver cells to establish a new model for hepatocyte steatosis due to their differentiation characteristics, which are similar to normal hepatocytes, but with the character of immortalization. Furthermore, it is easier to culture Chang liver cells than primary cells. Therefore, the results were closer to the characteristics of ideal NAFLD models developed from normal hepatocytes. However, there are fewer reports about the establishment of hepatocyte steatosis by Chang liver cells.

$\mathrm{OA}$ is a monounsaturated fatty acid mainly found in vegetable oil. Many studies have shown that hepatocytes can uptake the long-chain fatty acids, with $\mathrm{C} 12-\mathrm{C} 18$, and esterify them into neutral fat droplets that are then stored inside them. Following these ideas, Okamoto et al. (2002) were the first to induce HepG2 using OA for $24 \mathrm{~h}$ and establish a model for hepatocyte steatosis successfully. Years later, Yang and Chen (2007) used low concentrations of OA to induce L02 cells for $72 \mathrm{~h}$ and establish another model for hepatocyte steatosis.

In this study, we used different concentrations of OA to induce Chang liver cells for different periods. We determined the best inducing concentration and time to establish the model for hepatocyte steatosis using the MTT assay and Oil Red O staining. Combining the results from the MTT assay, Oil Red O staining, and TG detection, the fatty degeneration was obvious in the cells when they were induced by $0.2 \mathrm{mM}$ OA for $24 \mathrm{~h}$. As the induction time prolonged, namely above $48 \mathrm{~h}$, the fat droplets decreased. When the concentration of OA was more than $0.2 \mathrm{mM}$, even though fatty degeneration increased, the degree of cell injury increased gradually, which was similar to what was found by Yang and Chen (2007). These results showed that OA caused toxicity 
to the cells. A previous study showed that, when unsaturated fatty acid accumulated in hepatocyte, lipid peroxidation could be caused by the cytochrome P450 2E1 pathway, promoting apoptosis that led to cytotoxicity (Sung et al., 2004). Cui et al. (2010) found that the content of SOD-1 decreased significantly in hepatocytes induced by OA, which could explain the role of this enzyme in protecting the membrane from the free radicals attack in lipid peroxidation. Therefore, the cytotoxicity of OA can be related to lipid peroxidation and the decrease of the cell antioxidant capacity.

In our study, the required time for establishing the model of hepatocyte steatosis was shorter than in other studies, which, together with the conveniences of cell source and character stability, makes it an ideal method to study NAFLD.

\section{Conflicts of interest}

The authors declare no conflict of interest.

\section{ACKNOWLEDGMENTS}

Research supported by the National Natural Science Foundation of China (\#81160506 and \#81360669) and the Xinjiang Uygur Autonomous Region in University Research Project (\#XJEDU2014).

\section{REFERENCES}

Cui W, Chen SL and Hu KQ (2010). Quantification and mechanisms of oleic acid-induced steatosis in HepG2 cells. Am. J. Transl. Res. 2: 95-104.

Day CP and James OF (1998). Steatohepatitis: a tale of two "hits"? Gastroenterology 114: 842-845

Feldstein AE, Werneburg NW, Canbay A, Guicciardi ME, et al. (2004). Free fatty acids promote hepatic lipotoxicity by stimulating TNF-alpha expression via a lysosomal pathway. Hepatology (Hoboken, NJ, U. S.) 40: 185-194.

Gómez-Lechón MJ, Donato MT, Martínez-Romero A, Jiménez N, et al. (2007). A human hepatocellular in vitro model to investigate steatosis. Chem.-Biol. Interact. 165: 106-116.

Kleiner DE, Brunt EM, Van Natta M, Behling C, et al. (2005). Design and validation of a histological scoring system for nonalcoholic fatty liver disease. Hepatology (Hoboken, NJ, U. S.) 41: 1313-1321.

Kobashi-Margáin RA, Gutiérrez-Grobe Y, Ponciano-Rodríguez G, Uribe M, et al. (2010). Prevalence of type 2 diabetes mellitus and chronic liver disease: a retrospective study of the association of two increasingly common diseases in Mexico. Ann. Hepatol. 9: 282-288.

Lv Y C, Liu YX, Wu W, Zhou F, et al. (2011). Intervention of blueberry polyphenols on oleic acid induces fat accumulation in HepG2 cells. Shipin Kexue 32: 308-312.

Okamoto Y, Tanaka S and Haga Y (2002). Enhanced GLUT2 gene expression in all oleic acid-induced in vitro fatty liver model. Hepatol. Res. 23: 138-144.

Sung M, Kim I, Park M, Whang Y, et al. (2004). Differential effects of dietary fatty acids on the regulation of CYP2E1 and protein kinase C in human hepatoma HepG2 cells. J. Med. Food 7: 197-203.

Yang LH and Chen DF (2007). The establishment of oleic acid-induced hepatic steatosis culture model. Chongqingyixue 36: 698-700 